\title{
Mitral Valve Repair with a Malleable Bovine Pericardium Ring
}

\author{
Marco Antônio Volpe, Domingo Marcolino Braile, Reinaldo W ilson Vieira, Dorotéia Rossi Silva Souza
}

\author{
Campinas, SP - Brazil
}

\begin{abstract}
Objective - To describe a surgical procedure utilizing a malleable bovine pericardium ring in mitral valve repair and clinical and echodopplercadiographic results.

Methods - Thirty-two (25 female and 7 male) patients, aged between 9 and $66(M=36.4 \pm 17.2)$ years, were studied over a 16-month period, with 100\% follow-up. In 23 (72\%) of the patients, the mitral approach was the only one applied; 9 patients underwent associated operations. The technique applied consisted of measuring the perimeter of the anterior leaflet and implanting, according to this measurement, aflexible bovine pericardium prosthesis for reinforcement and conformation of the posterior mitral annulus, reducing it to the perimeter of the anterior leaflet with adjustment of the valve apparatus.
\end{abstract}

Results - The patient survival ratio was $93.8 \%$, with $2(6.2 \%)$ fatal outcomes, one from unknown causes, the other due to left ventricular failure. Only one reoperation was performed. On echodopplercardiography, $88 \%$ of the patients had functional recovery of the mitral valve $50 \%$ without and $38 \%$ with mild insufficiency and no hemodynamic repercussions). Of four (12\%) of the remaining patients, $6 \%$ had moderate and $6 \%$ had seigre insufficiency. Twenty-eight percent of class II patients and $72 \%$ of class III patients passed into classes I (65\%), II (32\%), and III (3\%), according to NYHA classification criteria.

Conclusion - Being flexible, the bovine pericardium ring fit perfectly into the valve annulus, taking into account its geometry and contractility. Valve repair was shown to be reproducible, demonstrating significant advantages during patient evolution, which did not require anticoagulation measures.

Key words: mitral valve surgery, annuloplasty, bovine pericardium

Faculdade de Ciências Médicas da Universidade Estadual de Campinas-UNICAMP Mailing address: Marco Antonio Volpe - Rua Baronesa do Japi, 129/13 - 13207000 - Jundiaí, SP - Brazil
To achieve perfect functioning of the mitral valve, it is necessary to maintain the functional integrity of its constituent elements, avoiding the effects of alteration consequent to congenital or acquired disease ${ }^{1}$. These are capable of causing valve annulus dilatation, commissure fusion, posterior cusp hypoplasia, shortening or lengthening of tendinous chords, and anterior or posterior chord rupture, leading to mitral insufficiency or stenosis ${ }^{2}$.

Lillehey and collaborators in 1956 performed the first annuloplasty to correct mitral insufficiency, under direct vision ${ }^{3}$. Subsequently, other surgeons attempted to generalize annuloplasty by using annulus plication ${ }^{4}$. However, this procedure led to a high rate of recurrence due to dehiscence, thrombosis, loss of cusp complacency, and other problems 5 .

The introduction of valve substitutes led to loss of interest in conservative procedures, and only a few groups continued to perform valve repair in selected cases ${ }^{6,7}$. Prosthesis diversity kept increasing, but patients with valve substituents started to experience complications, like fractures, wear and tear, thromboembolism, infection, hemolysis, rupture, and calcification, directly or indirectly associated with the prostheses ${ }^{7-9}$.

Interest in mitral reconstruction returned in the seventies with the work of Carpentier et al., who proposed the utilization of a rigid prosthetic ring for mitral valve reconstruction ${ }^{7,10,11}$. These authors also developed several techniques for the correction of specific anatomical valve abnormalities among which were segmental resection of the posterior leaflet as well as chord shortening, lengthening, grafting, and division ${ }^{11}$. These techniques started to be used together with annuloplasty for recovery of valve function ${ }^{7,12}$. Accumulated experience and new concepts about the physiology of the mitral valve apparatus showed the limitations of this technique, such as fixation of the contractile annulus ${ }^{13,14}$ and eventual obstruction of left ventricle outflow ${ }^{15-19}$.

Complete rings developed by Duran et al. ${ }^{13,20}$ and by Puig et al. ${ }^{21,22}$ followed principles similar to these proposed by Carpentier and colleagues, with the advantage of flexibility respecting native annulus motility ${ }^{13,20-22}$, and reduction of possible obstruction of left chamber outflow tract ${ }^{23}$. Yet, 
the anterior valve annulus does not participate, to an expressive extent, in the dilatation of the mitral apparatus, and the placing of a complete annular prosthesis may distort it, harming the left ventricleoutflow tract. This observation led to the proposal of an exclusively posterior prosthesis annuloplasty ${ }^{26}$ or of a merely continuous suture, similar to a "De Vega" ${ }^{25}$. Evolution confirmed the superiority of rings for posterior conformation ${ }^{26-30}$.

Valve repair techniques using rings are based on the anterior leaflet area, associated or not with intertrigonal or intercommissural distances for the selection of annular prosthesis size ${ }^{10,13,27-30}$. In 1985, Braile et al. ${ }^{26}$ developed specific measuring devices aimed at the evaluation of the anterior cusp perimeter, thus introducing a new concept for the choice of annular prosthesis size. They utilized a flexible, radiopaque bovine pericardium ring for reinforcement and remodeling of the posterior mitral annulus, reducing it to the perimeter of the anterior leaflet.

The present study had as its objective the description as well as postoperative clinical and echodopplercardiographic evaluation of a mitral valve repair technique using malleable bovine pericardium rings.

\section{Methods}

Thirty-two (25 female and 7 male) patients aged between 9 and $66(M=36.4 \pm 17.2)$ years were studied. Patients were operated upon with mitral valve repair with malleable bovine pericardium prostheses implanted in the posterior annulus, between August '94 and December'95 at the Cardiac Surgery Clinic of the Surgery Department of the School of Medical Sciences of the State University of Campinas.

Rheumatic disease was the cause of valve lesions in 28 $(87.5 \%)$ of the subjects, followed by myxomatous degeneration in $4(12.5 \%)$. Only one patient had had previous surgery for replacement of the aortic valve by a mechanical prosthesis. Table I presents the lesions that called for valve repair, emphasizing double mitral lesions, detected in 14 (44\%) and pure mitral insufficiency detected in 12(37\%) of the patients.

The period of extracorporeal circulation varied from 51 to 132 (mean, $80.2 \pm 18.8$ ) minutes, and aortic clamping varied between 29 and 100 (mean, 57.9 16.1 ) minutes. Cardioplegics were administered by continuous infusion. Twentyfive, 27, 29, and 31-mm rings were used.

\begin{tabular}{|lcc|}
\hline \multicolumn{2}{|c|}{$\begin{array}{l}\text { Table I - Preoperation valve lesions of patients who underwent } \\
\text { mitral valve repair with a malleable bovine pericardium ring }\end{array}$} \\
\hline \multicolumn{2}{|c|}{ Patients } \\
\hline Lesions & $\mathrm{N}^{\mathrm{o}}$ & $\%$ \\
\hline & 14 & 44 \\
Double mitral lesion & 12 & 37 \\
Pure mitral insufficiency & 5 & 16 \\
Pure mitral stenosis & 1 & 3 \\
Calcified mitral stenosis & 32 & 100 \\
Total & & \\
\hline
\end{tabular}

Table II shows the $23(72 \%)$ procedures and the 9 (28\%) operations associated with the plastic surgery. Mitral commissurotomy and tricuspid plastic were prominent procedures and operationsperformed in 18 and 4 of the patients, respectively.

Clinical evaluation according to the New York Heart Association (NYHA) was done in the pre- and postoperative periods. Figure 1-A shows $23(72 \%)$ functional class III and $9(28 \%)$ functional class II preoperative patients.

\begin{tabular}{|llcc|}
\hline $\begin{array}{l}\text { Table II - Procedures and operations associated with mitral valve } \\
\text { repair with a malleable bovine pericardium ring }\end{array}$ \\
\hline Associated procedures & \multicolumn{2}{c|}{ Patients } \\
\cline { 2 - 4 } & $\mathrm{N}^{\circ}$ & $\%^{*}$ & $\%^{* *}$ \\
\hline Anterior and posterior commissurotomy & 17 & 74 & 53 \\
Posterior papillarotomy & 3 & 13 & 10 \\
Anterior papillarotomy & 2 & 9 & 6 \\
Quadrangular resection of & 1 & 4 & 3 \\
the posterior cusp & 23 & 100 & 75 \\
Total & No & $\% *$ & $\% * *$ \\
\hline Associated operations & 4 & 45 & 13 \\
\hline Tricuspid valve repair & 3 & 33 & 9 \\
Aortic valve replacent & 2 & 22 & 6 \\
Aortic valve repair & 9 & 100 & 28 \\
Total & & & \\
\hline * Percentage of total number of procedures or associated operations; ** & & & \\
percentage of the total 32 patients. & &
\end{tabular}

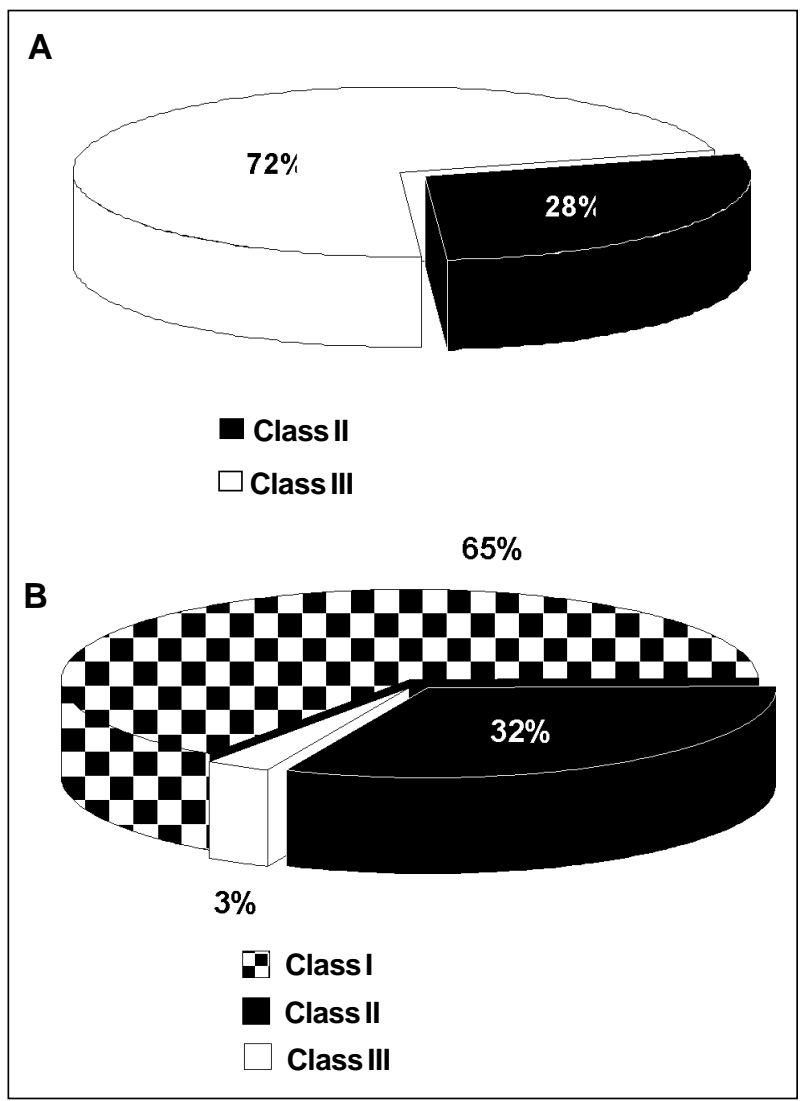

Fig. 1 - Clinical evaluation of patients who underwent preoperative postoperative with a malleable ring of bovine pericardium. (A) Preoperation; (B) postoperation. 
Degrees of mitral insufficiency were evaluated preand postoperatively by echodopplercardiography. Severe mitral insufficiency was detected in $75 \%$ of the patients, 12 $(37.5 \%)$ with pure insufficiency and $12(37.5 \%)$ with double lesions and a component of severe insufficiency. Of the remaining patients, two $(6 \%)$ had double mitral lesions and a moderate insufficiency component, and $6(19 \%)$ did not show insufficiency but had mitral stenosis (fig. 2-A).

In-hospital deaths occurred in the institution or within 30 days following surgery.

All patients underwent a medial sternotomy and systemic heparinization according to their activated coagulation time ( $\geq 480 \mathrm{~s})$. Following aortic cross clamping, infusion of blood cardioplegics was started from the aortic root, with a 12 Fr cannula.

The right atrium was opened and a purce string around the coronary sinus was made for introduction of a Foley o 18 for continuous retrograde infusion of cardioplegics. The left atrium was opened by a longitudinal incision in the direction of the lower vena cava and below the upper caval vein.

Adequate viewing of the mitral valve permitted the study of the valve's anatomy and the evaluation of extant

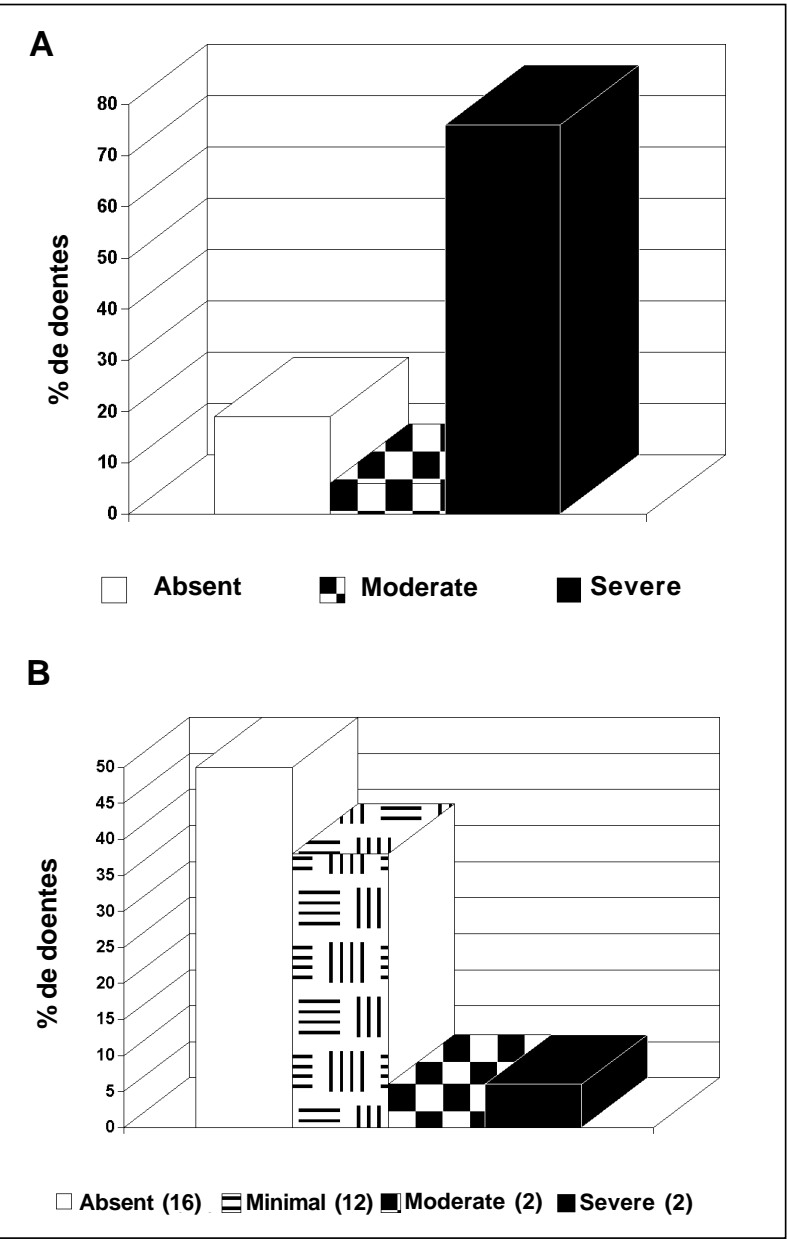

Fig. 2 - Echodopplercardiographic evaluation of patients who underwent mitralplasty with a malleable ring of bovine pericardium. (A) Preoperative; (B) Postoperative.
Mitral valvuloplasty with a malleable bovine pericardium ring

damage to the subvalvar apparatus. Lengthening, retraction, or rupture of the tendinous chords, as well as position and participation of the papillary musculature in the lesion were carefully evaluated. Two hooks with blunted, curved tips were utilized for gentle traction of the valve leaflets. When necessary, the tendinous chords, papillary muscles, and leaflets were handled. In the next step, measuring devices for the choice of the ring's size were utilized. These instruments come in pairs and sustain in their extremes 21 , $21 / 23,25 / 27$, and 29/31 mm semicircles (fig. 3) for measurement of anterior leaflet perimeter (fig. 4).

In the following sequence, $\mathrm{U}$-form stitches of 2.0 braided polyester thread were passed deep under the posterior mitral annulus, having as limits the two fibrous trigones and avoiding the coronary system. The same stitches were passed through the malleable ring and tied to retrieve the posterior mitral annulus, remodeling it to adequately fit the posterior to the anterior leaflet, guaranteeing valve competence (figures 5 and 6 ). The mitral valve was tested by passing a $12 \mathrm{~F}$ probe through the aortic valve orifice to the left ventricle, with infusion of the blood supplied by the arterial line via a shunt. After the test, when necessary, an additional repair was performed without difficulty, because the flexible rings allowed for a renewed approach to the valve, even after it was fixed. Testing was done until complete and adequate valve repair was achieved, and was followed by closing of the left atrium. After maneuvering to remove air from the cardiac cavities, cardioplegic infusion was

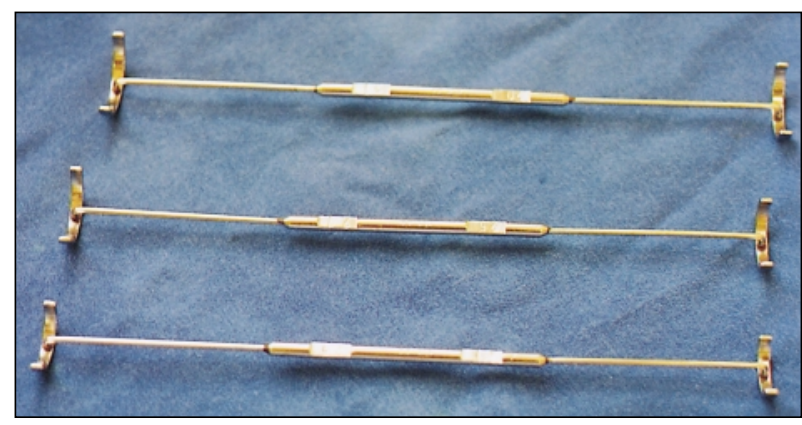

Fig. 3 - Anterior leaflet perimeter measuring devices.

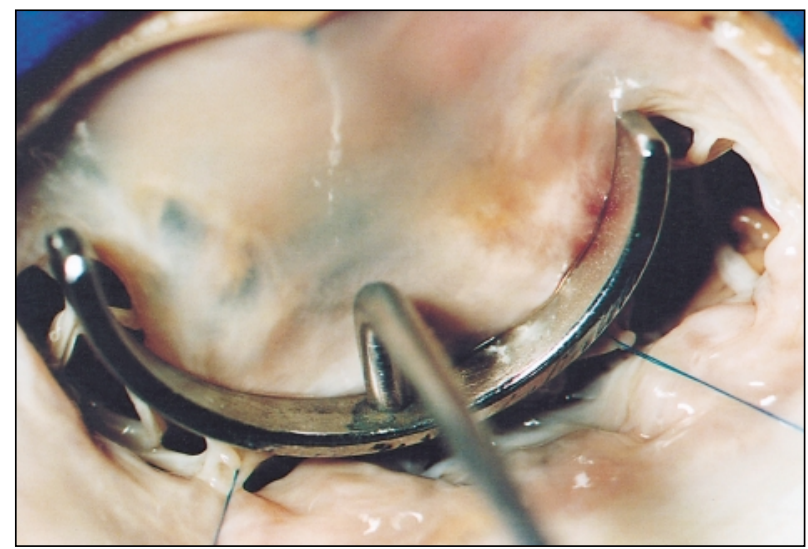

Fig. 4 - Anterior leaflet perimeter measurements. 


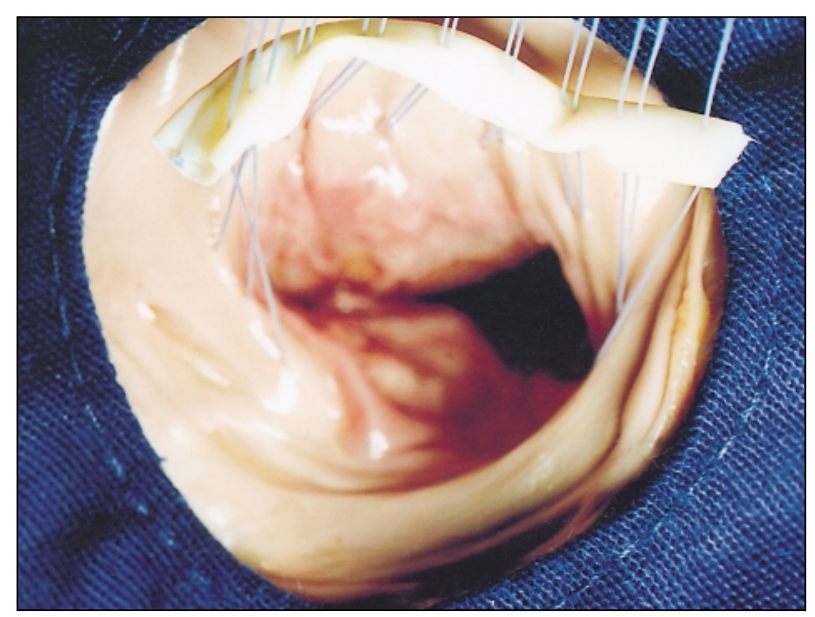

Fig. 5 - Stitches passed through the posterior mitral annulus and the malleable bovine pericardium prosthesis.

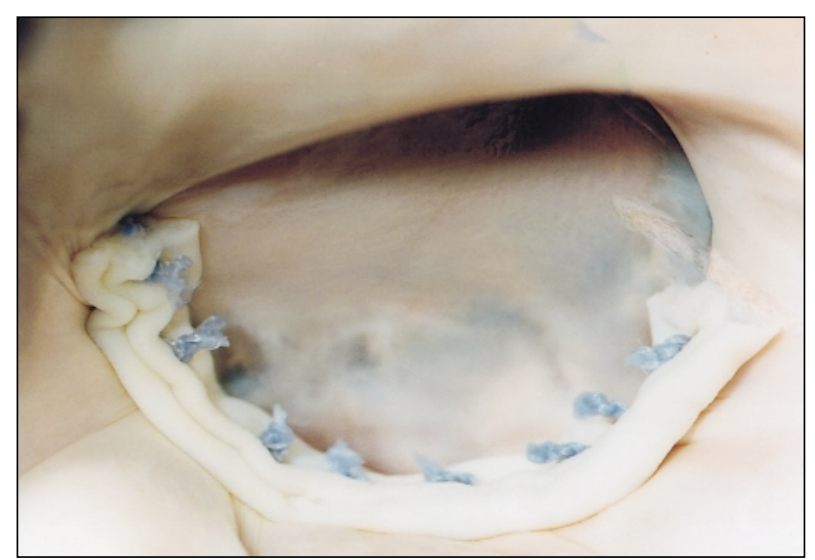

Fig. 6 - Malleable ring in its definitive position, with adequate valve closing.

stopped, and the aorta was unclamped; return of heartbeats occurred within a short time.

Clinical and echodopplercardiographic evaluations were performed based on the clinical history and pre- and postoperative examinations. The clinical classification was in agreement with the NYHA. Echodopplercardiographic evaluations by the transthoracic route used the ULTRAMARK - 4 apparatus from ATL (Advanced Technology Laboratories) with 2.25, 23.3, and 5.0 MHZ transducers. The classification proposed by Colette et al. ${ }^{31}$ and described by Feigenbaum ${ }^{32}$, which quantifies mitral insufficiency based on the extension and magnitude of the regurgitation jet during left ventricular systole was used. Classes were identified as absent - no detectable regurgitating jet; minimal discrete, non-holosystolic jet regurgitation restricted to the vicinity of the mitral valve; moderate - considerable, holosystolic regurgitation reaching the roof of the left atrium; severe - marked, holosystolic regurgitation reaching the roof of the left atrium; caught up to the level of the entrance of the pulmonary veins.

For a statistical analysis of the clinical and echodopplercardiographic evaluations Wilcoxon's test for paired data was used. Differences between values obtained pre- and postoperatively were considered significant when the statistical probability of their casualty was $<5 \%$.

\section{Results}

During the evolution of the 32 patients, two death occurred, one immediate, the other delayed. Both patients had a rheumatic valve pathology and severe mitral and tricuspid valve insufficiency, and underwent valve repair and associated procedures in both valves. One of these patients, 19 years old, died on the third day following the operation from unknown causes; the other, nine years old, had to be reoperated upon for mitral valve replacent nine months following valve repair. During evolution, he required prolonged ventilator support and experienced hemodynamic instability evolving into left ventricular failure, leading to death on the second day following the operation. All other patients were followed for 15 months, an equivalent of 214 months patients, with an average evolution time of 6.7 months.

No fatal late complications directly related to the malleable ring occurred, which allows a survival index of $93.8 \%$. One patient was re-operated upon nine months after mitral valve repair, with replacement of the valve due to the recurrence of the rheumatic process and development of important delayed post-operation insufficiency. Thus, the reoperation index was $3 \%$, coinciding with the index of nonfatal delayed complications.

Clinical pre- and postoperation evaluations were made on the basis of the NYHA classification. Figure 1 shows that on a comparative evolution analysis of 31 patients, 20 (65\%) passed on to functional class I; $10(32 \%)$ to class II, and only one (3\%) stayed in class III after reoperation.

Echodopplercardiographic studies shown on figure 2, allow comparison of pre- and postoperation findings and reveal that of the 32 patients; $16(50 \%)$ had an evolution free of insufficiency, $12(38 \%)$ had minimal insufficiency without hemodynamic repercussions, $2(6 \%)$ had moderate, and 2 $(6 \%)$ had severe insufficiency.

Wilcoxon's test for paired data showed statistically significant differences for functional class and echodopplercardiographic evolution between pre- and post-operation.

\section{Discussion}

This work proposes the utilization of a biological ring restricted solely to the posterior part of the mitral annulus. It differs from the flexible synthetic ring developed by Duran and Ubago ${ }^{13}$ of the second ring generation ${ }^{21}$ by not involving the whole mitral valve circumference. During evolution, it was shown to be satisfactory in patients who underwent annuloplasty, in agreement with previously presented results $26,28,29$.

In the decision for either valve repair or replacement, adequate patient selection and presence of associated risk factors should be considered ${ }^{33}$. In a multivariate analysis, Galloway and collaborators ${ }^{33}$ by combining age, sex, and 
various risk factors recorded four elements related to increased operation risk: age, functional class IV of the NYHA, previous cardiac surgery, and presence of previous cardiac interventions. According to the authors, the type of surgical valve conduct does not seem to influence operation risk or late survival of patients who undergo valve repair or replacement. However, for Carpentier ${ }^{11}$ valve reconstruction is to be indicated for all lesions, even prior to consideration of age, cause of the disease, and patient condition. Furthermore, the younger the patient, the more urgent such an indication becomes.

In the present work, echodopplercardiography reaffirmed the indication for reparative surgery in patients with functional class II (28\%) before they developed greater lesions of the valve apparatus and evolution to ventricle deterioration. This permitted the achievement of a better result, $65 \%$ of the patients passing to functional class I with recovery of left ventricular geometry and mechanical function of the mitral valve, as is also reported in the literature ${ }^{26,28,34,35}$. A follow-up period of 16 months showed a survival ratio of $93.8 \%$; other studies, with lower ${ }^{29}$ or equal ${ }^{36}$ follow-up periods, reported $98 \%$ indexes. Studies with follow-up periods of five ${ }^{26,28}$, eight ${ }^{35}$ and $16^{34}$ years, reported survival rates of respectively, 90 to $98.8 \pm 1.2 \%, 88 \pm 4 \%$, and $76.1 \pm-$ $3.1 \%$. It is common to find valve repair leading to a higher survival rate in comparison with valve replacement ${ }^{37}$.

Acquired experience, understanding of the role of the mitral valve apparatus in left ventricular function, and decreased postoperative morbidity and mortality led to the expansion of the number of valve repair interventions ${ }^{30,38}$ known ${ }^{39}$ to lead to a better postoperative performance of the left ventricle as well. Long-term results showed ventricular function restored to normal levels, significantly improved survival ratios in particular following solely mitral procedures ${ }^{34}$, which in the present work were performed in $71.8 \%$ of the patients. Associated with this was the introduction of various valve repair techniques ${ }^{13,21,40,41}$ as well as recognition of the problems caused by valve replacement procedures like prosthesis degeneration, infection, transvalvular gradients, paravalvular leaking, hemolysis, and thromboembolic events ${ }^{8,37}$.

Compared with valve replacement, repairs is associated with fewer complications ${ }^{33,42}$. In this study, postoperative complications occurred in $3.1 \%$ of the cases, coinciding with reoperation in a patient with rheumatic valve pathology and severe mitral and tricuspid insufficiency, who underwent repair procedures in both valves. During later evolution, this patient required mitral valve replacement, which however, led to death. The literature shows a reoperation-free ratio of patients who undergo valve repair, fluctuating between 49 and $100 \%$ during a follow-up period of 4 to 17 years ${ }^{26,30,33,43,44}$. The lower ratio was not always related to a longer follow-up period.

Analysis of mitral valve repir reveals the importance of annulus remodeling using some type of prosthesis, bearing in mind that the absence of annuloplasty is associated with a higher incidence of precocious failure ${ }^{30}$. A study by
Bernal et al. ${ }^{34}$, utilizing a complete, malleable ring, revealed that $89.9 \pm 3.2 \%$ of their rheumatic patients remained free of reoperation over a 16-year period. In this case, the risk of reoperation curve showed two critical periods with a high incidence, during the first two years, and 10 years after surgery. According to the authors, precocious reoperation is habitually associated with an inadequate indication or technical, while delayed indications are in general, connected to the progress of the valve's basic pathology. In the present study, however, such a progress precociously determined reoperation.

In contrast, Braile and collaborators ${ }^{26}$ revealed the absence of reoperation after a follow-up period of five years of patients with predominantly rheumatic valve pathology who underwent posterior annuloplasty ${ }^{26}$. Nevertheless, rheumatic valve pathology is worrisome, with a high incidence of failure in the reparation procedures ${ }^{11,33,43}$. These are probably due to histopathological alterations occurring in the mitral valve during rheumatic disease, including among others, intercellular edema, collagen fiber fragmentation, and lymphocyte and plasma cell infiltration. Nevertheless, Bernal et al. ${ }^{34}$ and Antunes et al. ${ }^{43}$ affirm that valvalve repair is an excellent alternative for the treatment of patients with rheumatic mitral valve disease.

David et al. ${ }^{35}$, using a complete, malleable ring in patients with degenerative valve pathology, found $95 \pm 2 \%$ free from reoperation for more than 8 years. They concluded that only an advanced degree of myxomatous alterations was related to a greater risk of reoperation. Cosgrove et al. ${ }^{29}$, in a study of patients with predominantly degenerative valve pathology treated with posterior annuloplasty, observed $97 \%$ of them to be free of reoperation for a year, and Camilleri et al. ${ }^{28}$ found $99 \%$ of patients to be free of this event for over 5 years. Controversy exists over the reoperation ratio associated with valve repair ou replacement. Galloway et al. ${ }^{33}$ and Cosgrove ${ }^{44}$ report similar indexes for both procedures, but some studies show higher values for plastic surgery ${ }^{45}$.

Valve repair in rheumatic disease is associated with a higher index of thromboembolic complications, in comparison to similar procedures in a degenerative or ischemic valve pathology ${ }^{34}$. In the present study, although $87.5 \%$ of the patients had a rheumatic valve pathology, no thromboembolic episodes were registered even in the absence of anticoagulants in patients who received only oral treatment with a dose of $200 \mathrm{mg} /$ day of acetylsalicylic acid, which is in agreement with Braile et al. ${ }^{26}$ whose predominantly rheumatic valve pathology patients underwent the same technique and a five-year follow-up period.

Bernal et al. ${ }^{34}$ found $79.2 \pm 3.2 \%$ of carriers of rheumatic valve pathology who underwent mitral valve repair with the complete malleable ring to be free of this complication over a period of 16 years. A peak in the thromboembolism curve was observed 10 years following the operation, coinciding with one of the peaks of the reoperation curve. This places the valve rather than the type of technique employed as the probable responsible factor for this complication. Thromboembolism also appears to be related, along with the cause of 
the lesion, to preoperative risk factors, rather than to the surgical procedure proper ${ }^{34,35}$.

David et al. ${ }^{35}$ found after an eight-year follow-up lesser indexes of absence of thromboembolism, below $82 \pm 6 \%$, in patients who underwent valve repair for degenerative mitral disease. An association between age (above 60 years) and a threefold higher risk of occurrence of this event was found. In the present study, this age group was represented by only $12.5 \%$ of the patients. In contrast, considering only predominantly degenerative valve pathology, Camilleri et al. ${ }^{28}$ and Cosgrove et al. ${ }^{29}$ observed 97 and $91 \%$ of patients to be free of this complication after follow-up periods of, respectively, one and five years.

Endocarditis, not observed in this study also shows a low incidence in other literature reports. It was observed by Bernal et al. ${ }^{34}$ in $0.8 \%$ of patients having rheumatic valve pathology, followed for 16 years.

In a study of patients with a predominance of rheumatic valve pathology, Braile et al. ${ }^{26}$ found $95.7 \pm 4.5 \%$ of them not to have this complication. The index for degenerative valve pathology varied between 98 and $100 \%$ during a follow-up period of one to eight years ${ }^{28-30,35}$.

In the present work, mitralvalve repair, normally performed in patients with a diagnosis of insufficiency or double lesion, was also indicated for carriers of mitral stenosis or calcification (19\%) following commissurotomy. The technique was effective in cases where, following this procedure, the valve had some insufficiency and was found to be of importance for postoperation evolution. The malleable bovine pericardium ring enabled a decrease in the area that the leaflets, with adequate coaptation, should close. This allowed for the recovery of the relationship between the valve annulus and the cusps, whose variation falls between $1: 1.5$ and $1: 22^{30,46}$.

Benefits were seen with echodopplercardiography, revealing an $88 \%$ recovery of valve function, regurgitation being either absent $(50 \%)$ or minimal $(39 \%)$ with a discrete, nonholosystolic jet restricted to the vicinity of the mitral valve, according to the classification proposed by Colette et al. ${ }^{31}$. It is believed that one of the factors determining the success of this technique lies in the measurement of the anterior cusp's perimeter in the choice of the size of the prosthesis to be used in the posterior mitral annulus. Differing annuloplasty adopts as a basis for measurement in the choice of the different size rings, the intertrigonal or intercommissural distance, associated or not with the measurement of the anterior leaflet's area ${ }^{10,13,27-30}$. Yet, the mitral annulus does not maintain size and form constant during systole and the annulus segment over the area of aortic-mitral continuity is significantly lengthened during ventricular systole ${ }^{47}$. Thus, such measurements do not seem to favor an adequate estimate for the selection of annular prosthesis' size, justifying the development of devices to measure anterior cusp perimeters ${ }^{26}$.

Nagastu et al. ${ }^{48}$ experimentally demonstrated that following mitral valve repair a fraction of the regurgitation of $\leq 30 \%$ is associated with full recovery of the contractile function, alterations occurring at the cellular (myocyte) level. Clinical evidence indicates pronounced improvement in diastolic functional response as well as of volume and dimension of the left ventricle during a follow-up period of one year ${ }^{14}$; this carries promise for the evolution of the patients studied in this work.

Reconformation of the mitral annulus enables a directimprovement of the cardiac muscle with a reduction in diastolic diameter of the left ventricle, as demonstrated in studies with longer follow-up periods ${ }^{26,28,34,35}$. Braile et al. ${ }^{26}$ reported a significant difference in the pre- and postoperation relationship between aortic and left ventricle diameters, with reacquisition of normal values for this relation in the late postoperative period. These findings confirm the description of a dilatation of the mitral annulus occurring mainly in its posterior portion, with a symmetric or asymmetric pattern, depending on the type of disease ${ }^{49}$. Thus, the anterior portion of the annulus apparently does not require reconformation ${ }^{26,30}$.

However, the success obtained in annuloplasty using rings did not prevent the use of rigid prostheses for mitral valve repair ${ }^{10,27}$, a situation that has generated discussion about the real performance of the various types of prostheses in dilated valve annulus remodeling. Knowledge about the dynamic properties of the native mitral ring confirms the absence of its position fixed in a geometric plane, because its saddle format allows for a large flexion during systole $(28,30)$. In normal situations, the valve annulus has a sphincter-like function, with an approximately $26 \%$ reduction in its area during ventriclar systole, acquiring an elliptical form, while in diastole it has a circular shape ${ }^{30}$. Therefore, insertion of a rigid ring could interfere with these properties in a negative manner ${ }^{26,28-30,34}$. Due to its characteristics, bovine pericardium adapts itself perfectly to the mitral ring, not interfering with its contractility ${ }^{26}$, leading to the satisfactory evolution of the patients verified in this study.

In choosing the prosthesis for valve repair, it is important to consider the cause of the disease. Thus, for patients with mitral regurgitation due to a degenerative valve pathology and a contractile mitral annulus, flexible prostheses are indicated, but for those with regurgitation due to a rheumatic valve pathology and a valve annulus with impaired contractility, both types would be of benefit to left ventricular function. Avoidance of a drastic change from a regularly contractile annulus to a rigid one ${ }^{14}$ is recommended.

Spence et al. ${ }^{50}$, in an experimental study comparing different types of annular prostheses, concluded that the rigid ones harm systolic function of the left ventricle. At a later date, the same group clinically confirmed this by reporting such rings to be a determinant for depressed ventricular function ${ }^{14}$, and supporting the use of malleable rings in carriers of a rheumatic valve pathology with reduced annular contractility, as occurred in $87.6 \%$ of the presently studied cases. Furthermore, the rigid ring may also cause the obstruction of the left ventricular outflow tract observed in 4.5 to $10 \%$ of the cases ${ }^{15-18}$, a fact not observed in annuloplasty with completely flexible rings ${ }^{14,31}$ or with flexible posterior rings ${ }^{26,28,29}$, results of the present study included. 
In conclusion, the bovine pericardium ring was shown to be flexible, fitting itself perfectly to the valve annulus, respecting its geometry and contractility. It appears legitimate to affirm that mitral lesions due to different causes, including insufficiency secondary to surgical treatment of mitral stenosis, may be adequately treated by the presently proposed technique, considering that $65 \%$ of the patients evolved to functional class I and $88 \%$ achieved complete recovery of valve function without needing anticoagulation.

\section{Acknowledgement}

We thank Drs. Valentim Baccarin, Orlando Petrucci Jr. and Pedro Paulo Martins Oliveira for support received during this work.

\section{References}

1. Perloff JK, Roberts WC. The mitral apparatus. Functional anatomy of mitral regurgitation. Circulation 1972; 46: 227-39.

2. Cosgrove DM, Stewart WJ. Mitral valvuloplasty. Curr Probl Cardiol 1989; 4: 359-415.

3. Lillehei CW, Gott VL, Dewall RA. Surgical correction of pure mitral insufficiency by annuloplasty under direct vision. Lancet 1957; 77: 446-9.

4. Bigelow WG, Kuypers PJ, Heimbecker RO, Gunton RW. Clinical evaluation of the efficiency of mitral annuloplasty. Ann Surg 1961; 154: 320-9.

5. Agathos EA, Starr A. Mitral valve replacement. Curr Probl Surg 1993; XXX: 481-600.

6. Reed GE, Pooley RW, Moggio RA. Durability of measured mitral annuloplasty: Seventeen-year study. J Thorac Cardiovasc Surg 1980; 79: 321-5.

7. Galloway AC, Colvin SB, Baumann FG, Harty S, Spencer FC. Current concepts of mitral valve reconstruction for mitral insufficiency. Circulation 1988; 78: 1087-98.

8. Reul GJ, Cooley DA, Duncan JM, et al. Valve failure with the Ionescu-Shiley bovine pericardial bioprosthesis: analysis of 2680 patients. J Vasc Surg 1985; 2: 192-204.

9. Braile DM, Volpe MA, Ramin SL, Souza DRS. Tratamento cirúrgico das valvopatias. In: Barretto ACP, Sousa AGMR, eds. Cardiologia: Atualização e Reciclagem. Rio de Janeiro: Atheneu, 1994: 476.

10. Carpentier A, Deloche A, Dauptain J, et al. A new reconstructive operation for correction of mitral and tricuspid insufficienty. J Thorac Cardiovasc Surg 1971; 61: $1-13$.

11. Carpentier A. Cardiac valve surgery - the "french correction". J Thorac Cardiovasc Surg 1983; 86: 323-37.

12. Galloway AC, Colvin SB, Baumann FG. Long-term results of mitral valve reconstruction with Carpentier techniques in 148 patients with mitral insufficiency. Circulation 1988; 78(suppl 1): 97-105.

13. Duran CG, Ubago JLM. Clinical and hemodynamic performance of a totally flexible prosthetic ring for atrioventricular valve reconstruction. Ann Thorac Surg 1976; 22: 458-63.

14. David TE, Komeda M, Pollick C, Burns RJ. Mitral valve annuloplasty: the effect of the type on left ventricular function. Ann Thorac Surg 1989; 47: 524-8.

15. Kreindel MS, Schiavone WA, Lever HM, Cosgrove DM. Systolic anterior motion of the mitral valve after Carpentier ring valvuloplasty for mitral valve prolapse. Am J Cardiol 1986; 57: 408-12.

16. Marwick TH, Stewart WJ, Currie P, Cosgrove DM. Mechanisms of failure of mitral repair: an echocardiographic study. Am Heart J 1991; 122: 149-56.

17. Krenz HK, Mindich BP, Guarino T, Goldman ME. Sudden development of intraoperative left ventricular outflow obstruction: differential and mechanism: an intraoperative two-dimensional echocardiographic study. J Cardiovasc Surg 1990; 5: 93-101.

18. Stewart WJ, Currie PJ, Salcedo EE, et al. Intraoperative doppler color flow mapping for decision-making in valve repair for mitral regurgitation: technique and results in 100 patients. Circulation 1990; 81: 556-66.

19. Grossi EA, Galloway AC, Parish MA, et al. Experience with twenty-eight cases of systolic anterior motion after mitral valve reconstruction by the Carpentier technique. J Thorac Cardiovasc Surg 1992; 103: 466-70.

20. Duran CMG, Ubago JL. Conservative mitral valve surgery. Problems and developments in the techniques of prosthetic ring annuloplasty. In: Kalmanson D, ed. The Mitral Valve. A Pluridisciplinary Approach. Massachussets: Publishing Sciences Group Inc., 1975: 549.

21. Puig Messana M, Calbet JM, Castells E. Conservative surgery of the mitral valve. Annuloplasty on a new adjustable ring. In: Bircks W, Ostemeyer J, Schulte HD, eds. Cardiovascular Surgery. Berlim: Springer-Verlag, 1981: 30.
22. Murphy JP, Sweeney MS, Cooley DA. The Puig-Massana-Shiley annuloplasty ring for mitral valve repair: experience with 126 patients. Ann Thorac Surg 1987; 43: 52-8.

23. Rey MJ, Mercier LA, Castonguay Y. Echocardiographic diagnosis of left ventricular outflow tract obstruction after mitral valvuloplasty with flexible Duran ring. J Am Soc Echocardiogr 1992; 5: 89-92.

24. Cooley DA, Frazier OH, Norman JC. Mitral leaflet prolapse: surgical treatment using a posterior annular collar prosthesis. Bull Tex Heart Inst 1976; 3: 438-42.

25. Czer LSC, Maurer G, Trento A, et al. Comparative efficacy of ring and suture annuloplasty for ischemic mitral regurgitation. Circulation 1992; 86(suppl II): 46-52.

26. Braile DM, Ardito RV, Pinto GH, et al. Plástica mitral. Rev Bras Cir Cardiovasc 1990; 5: 86-98

27. Gregori F, Silva SS, Baba K, et al. Um novo modelo de anel protético para pacientes com insuficiência valvar mitral. Relato de dois casos. Arq Bras Cardiol 1988; 50: 417-20.

28. Camilleri L, Filaire M, Repossini A, et al. Mitral annuloplasty with a flexible linear reducer. J Card Surg 1995; 10: 99-103.

29. Cosgrove DM, Arcidi JM, Rodriguez L, Stewart WJ, Powell K, Thomas JD. Initia experience with the cosgrove-edwards annuloplasty system. Ann Thorac Surg 1995; 60: 499-504.

30. Camilleri LF, Miguel B, Bailly P, et al. Flexible posterior mitral annuloplasty: five-year clinical and doppler echocardiographic results. Ann Thorac Surg 1998; 66: 1692-7.

31. Colette V, Ameur A, Sylvie BAS, Lessana A, Abitbol G, Kalmanson D. Pulsed doppler echocardiographic indices for assessing mitral regurgitation. Br Heart J 1984; 51: 130-8.

32. Feigenbaum H. Acquired valvular heart disease. In: Feigenbaum H, ed Echocardiography. Indianapolis: Lea \& Febiger, 1993: 239.

33. Galloway AC, Colvin SB, Baumann FG, et al. A comparison of mitral valve reconstruction with mitral valve replacement: intermediate-term results. Ann Thorac Surg 1989; 47: 655-62.

34. Bernal JM, Rabasa JM, VilchezFG, Cagigas JC, Revuelta JM. Mitral valve repair in rheumatic disease: the flexible solution. Circulation 1993; 88: 1746-53.

35. David TE, Armstrong S, Sun Z, Daniel L. Late results of mitral valve repair for mitral regurgitation due to degenerative disease. Ann Thorac Surg 1993; 56: 7-14

36. Carpentier AF, Lessana A, Relland JYM, et al. The "physio-ring": an advanced concept in mitral valve annuloplasty. Ann Thorac Surg 1995; 60: 1177-86.

37. Cohn LH, Kowalker W, Bhatia S, et al. Comparative morbidity of mitral valve repair versus replacement for mitral regurgitation with and without coronary artery disease. Ann Thorac Surg 1988; 45: 284-90.

38. Lillehei CW, LevyMJ, Bonnabeau RC. Mitral valve replacement with preservation of papillary muscles and chordae tendineae. JThorac Cardiovasc Surg 1964;47:532-43.

39. Goldaman ME, Mora F, Guarino T, Fuster V, Mindich BP. Mitral valvuloplasty is superior to valve replacement for preservation of left ventricular function: an intraoperative two-dimensional echocardiographic study. J Am Coll Cardiol 1987; 10: 568-75

40. Frater RWM, Gabbay S, Shore D, Factor S, Strom J. Reproducible replacement of elongated or ruptured mitral valve chordae. Ann Thorac Surg 1983; 43: 14-28.

41. Gregori F, Takeda R, Silva S, Facanha L, Meier MA. A new technique for repair of mitral insufficiency caused by ruptured chordae of the anterior leaflet. J Thorac Cardiovasc Surg 1988; 96: 765-8.

42. Craver JM, Cohen C, Weintraub WS. Case-matched comparison of mitral valve replacement and repair. Ann Thorac Surg 1990; 49: 964-9.

43. Antunes MJ, Magalhães MP, Colsen RR. Valvuloplasty for reumatic mitral valve disease. J Thorac Cardiovasc Surg 1987; 94: 44-56. 
44. Cosgrove DM. Mitral valve repair in patients with elongated chordae tendineae. J Cardiac Surg 1989; 4: 247-52.

45. Cohn LH. Mitral valve surgery: reconstruction versus replacement. In: International symposium advances in cardiology - controversial views. Berlim: Anais Berlim, 1984.

46. Brock RC. Surgical and pathological anatomy of the mitral valve. Brit Heart J 1952; 14: 489-513.

47. Glasson JR, Komeda M, Daughters GT, et al. Three-dimensional regional dynamics of the normal mitral anulus during left ventricular ejection. J Thorac Cardiovasc Surg 1996, 111: 574-85.
48. Nagatsu M, Ishihara K, Zile MR, et al. The effects of complete versus incomplete mitral valve repair in experimental mitral regurgitation. J Thorac Cardiovasc Surg 1994; 107: 416-23.

49. Galloway AC, Colvin SB, Baumann FG. Long-term results of mitral valve reconstruction with Carpentier techniques in 148 patients with mitral insufficiency. Circulation 1988; 78(suppl 1): 97-105.

50. Spence PA, Peniston CM, David TE, et al. Toward a better understanding of the etiology of left ventricular dysfuction after mitral valve replacement: an experimental study with possible clinical implications. Ann Thorac Surg 1986, 41: 363-71. 